\title{
Iron Dextran Complex
}

National Cancer Institute

\section{Source}

National Cancer Institute. Iron Dextran Complex. NCI Thesaurus. Code C44394.

A colloidal solution containing ferric oxyhydroxide complexed with polymerized dextran, used as a form of parenteral iron-replacement therapy. Upon administration and absorption, the iron dextran complex is removed from plasma by the reticuloendothelial system which cleaves it into the components iron and dextran; ferric iron subsequently binds to transferrin or is stored as hemosiderin or ferritin. Transferrin-bound iron is transported in the plasma to the liver, spleen and bone marrow, where is it is incorporated into hemoglobin $(\mathrm{Hgb})$ and to muscle where it is incorporated into myog lobin (Mb). Use of this agent circumvents the gastrointestinal adverse effects commonly encountered with the use of orally administered iron salt preparations. Because of cross-reactivity with antibodies targeted ag ainst polysaccharides similar to dextran, anaphylactic reactions may occur with this type of iron formulation. 